\title{
The AKT antagonist AZD5363 suppresses features associated with cancer progression in human larynx cancer cells
}

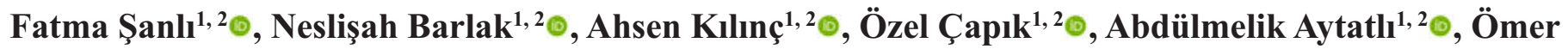 \\ Faruk Karataş ${ }^{1,2} \odot$
}

${ }^{1}$ Department of Molecular Biology and Genetics, Erzurum Technical University, Erzurum, Turkey

${ }^{2}$ Molecular Cancer Biology Laboratory, High Tecnology Aplication and Research Center, Erzurum Technical University, Erzurum, Turkey

\section{ABSTRACT}

Objectives: Larynx cancer (LCa) represents approximately $30 \%$ of all cancers seen in the head and neck region, with an unchanged overall survival rate over the last decades. Although several novel diagnostic and therapeutic options has been developed, an effective treatment strategy is not currently available due to the high metastatic and recurrent potential of LCa. In this study, we aimed at investigating the inhibitory potential of AZD5363 on the phenotypes associated with LCa progression in vitro.

Methods: The impacts of AZD5363 on the proliferation, colony formation, and apoptosis potentials of HEp2 cells were tested using Cell Viability Detection Kit-8, soft agar assay and Annexin V-FITC Apoptosis assay, respectively. Migration features of cells were evaluated using scratch and transwell migration assays.

Results: We showed that AZD5363 increased phosphorylation of AKT and inhibited the phosphorylation of its downstream effector GSK3 $\beta$ in an in vitro. LCa model in line with the findings of previous studies carried out with different cancer types. Besides, AZD5363 successfully suppressed proliferative, clonogenic, and migratory features of HEp-2 cells through induction of apoptosis.

Conclusions: We revealed putative functions of AZD5363 in vitro. that points its potential to be used as an adjuvant agent against LCa. However, further comprehensive molecular and clinical research is needed to elucidate the potential use of AZD5363 in LCa therapy in detail.

Keywords: Larynx cancer, AZD5363, AKT, chemotherapy

L arynx cancer ( $\mathrm{LCa})$, as a common reason for can$\checkmark$ cer-related mortality worldwide, represents approximately $30 \%$ of all cancers seen in the head and neck region $[1,2]$. Almost $40 \%$ of the LCa patients do not visit doctor until the last stage of the disease [3] and without treatment, patients have only $56.4 \%$ and $26.5 \%$ overall 1 - and 2-year survival rates, respectively $[4,5]$. Besides, although several novel diagnos- tic and therapeutic options such as surgery, radiotherapy, and chemotherapy are applicable for LCa patients, an effective treatment strategy is not present due to its high metastatic and recurrent potential [6]. Therefore, there is an urgent need to develop new treatment strategies and novel adjuvant therapies especially against advanced LCa to enhance the life expectancy and survival rates of LCa patients. 
Phosphoinositide 3-kinase/serine-threonine protein kinase B (also known as AKT)/mammalian target of rapamycin (PI3K/AKT/mTOR) signaling pathway is involved in numerous key processes including cell proliferation, apoptosis, and migration [7]. Abnormal activation of this signaling pathway in various types of cancers is quite common [8]. Loss of phosphatase and tensin homolog deleted on chromosome 10 (PTEN), the negative regulator of the $\mathrm{PI} 3 \mathrm{~K} / \mathrm{AKT} / \mathrm{mTOR}$ pathway, is a frequent event leading to activation of AKT signaling in various tumors such as breast, prostate, and larynx cancers [9-12]. AKT, which is the center of this signaling network, was reported to be overexpressed or activated in many malignancies $[13,14]$. Abnormal activation of AKT was related to resistance to anti-cancer drugs, poor survival and advanced disease [15]. In LCa, AKT2 was found to be strongly positive in cancerous and pericancerous tissues, although no protein expression was reported in normal laryngeal epithelium. AKT2 positivity in protein level was also significantly related to tumor site, lymph node metastasis and clinical stage [16]. In another study, elevated AKT3 expression was related to shorter overall survival of LCa patients [17]. Therefore, PI3K/AKT/mTOR pathway might serve as a crucial axis for development of novel treatment strategies against LCa.

AZD5363 [(S)-4-amino-N -[1-(4-chlorophenyl)3-hydroxypro pyl]-1-(7H-pyrrolo [2, 3-d] pyrimidin4-yl) piperidine-4- carboxamide] is a novel new-generation drug with inhibitory potential against AKT 1, 2, and 3 [18]. AZD5363 was found to suppress phosphorylation of AKT substrates including GSK3 $\beta$ in various cell lines and rodent xenografts models [18]. It has been shown to suppress the progression of various human tumor xenografts when administered alone or in combination with chemotherapeutics [19]. AZD5363 is currently being investigated in phase I clinical trials in patients with advanced solid tumors $[20,21]$. However, its activity against LCa cells is not yet documented.

We, therefore, examined the inhibitory potential of AZD5363 on the phenotypes associated with LCa progression in vitro We demonstrated that AZD5363 increases phosphorylation of AKT and inhibits its downstream effector GSK3 $\beta$ in an in vitro LCa model and AZD5363 successfully suppresses proliferative, clonogenic, and migratory features of HEp-2 cells through induction of apoptosis.

\section{METHODS}

\section{Cell Culture}

Hep2 cell line was received from SAP Institute, Turkey (Ministry of Food Agriculture and Livestock). Cells grown in RPMI (Gibco, Gaithersburg, MD, USA) medium containing 10\% Fetal Bovine Serum (FBS, Gibco, Gaithersburg, MD, USA), 1\% penicillin/streptomycin (Gibco, Gaithersburg, MD, USA) were cultured at $37^{\circ} \mathrm{C}$ in a humidified $5 \% \mathrm{CO} 2$ incubator. Cell culture medium was changed when the cell density reached $80-90 \%$ confluency.

\section{Preparation of AZD5363 Stock Solution}

AZD5363 (MedChemExpres, NJ,USA) was solubilized in dimethyl sulfoxide (DMSO). Its stock solution was prepared at $10 \mathrm{mM}$ concentration and stored at $-80^{\circ} \mathrm{C}$ until its use for in vitro experiments.

\section{Cell Proliferation Assay}

To determine the effect of AZD5363 on the viability of HEp-2 cells, Cell Viability Detection Kit 8 (CVDK-8, EcoTech Biotechnology, Turkey) was used. Briefly, cells seeded at $2.5 \times 10^{3}$ cells per well in 96 well plates were cultured overnight in the appropriate medium. Then AZD5363 was administered to cells at increasing concentrations for 24 and $48 \mathrm{~h}$. To measure changes in cell growth rate, CVDK- 8 reagent was added to each well according to the manufacturer's instructions. After $1 \mathrm{~h}$ incubation, absorbances were measured at 450nm with an Epoch 2 Microplate Spectrophotometer (BioTek, Winooski, VT, USA) to determine cell viability.

\section{Soft Agar Colony Formation Assay}

Soft agar assay was performed to investigate the effect of AZD5363 on HEp-2 cells' colonization potential. Cells at a concentration of $3 \times 10^{3} /$ per well within $0.3 \%$ agar in RPMI were plated on a $0.6 \%$ base agar in 6-well plates. Cells within agar were exposed to varying concentrations of AZD5363 at $37^{\circ} \mathrm{C}$ for 21 days. Cells were fixed and stained with $0.01 \%$ crystal violet solution containing $10 \%$ ethanol to visualize and count the colonies. 


\section{Apoptosis Assay}

Annexin V-FITC Apoptosis kit (BioVision, Milpitas, CA, USA) was used to observe the effect of AZD5363 applied at 1,5 and $10 \mu \mathrm{M}$ concentrations on apoptosis of HEp-2 cells cultured in 6 well plates at $2.5 \times 10^{5}$ cells per well. Following 48 hours of incubation of HEp-2 cells with AZD5363, cells were washed twice with cold PBS, harvested in $500 \mu \mathrm{L}$ binding buffer and then incubated with $5 \mu \mathrm{L}$ Annexin $\mathrm{V}$ and PI for 15 minutes at room temperature. Finally, the apoptotic state of HEp-2 cells was determined by CyFlow $^{\circledR}$ Cube 6 flow cytometry device.

\section{Scratch Assay}

HEp-2 cells were seeded in 6-well plates with a cell density of $5 \times 10^{5}$. After reaching $\% 90-100$ confluency, the areas where the cells are dense were detected and uniform wounds were opened with a sterile 100 $\mu \mathrm{L}$ pipette tip. Then, cells were treated with fresh medium containing the indicated concentrations of AZD5363 and the wounds were photographed with an inverted microscope (Leica, Wetzlar, Germany). After $24 \mathrm{~h}$, the migration potential of the cells was assessed by comparing the size of wound closure.

\section{Cell Migration Assay}

The transwell migration assay was performed to examine the chemotactic motility of HEp-2 cells. Firstly, serum-free medium containing $1 \times 10^{4}$ cells were placed in the migration chambers with a total volume of $250 \mu \mathrm{L}$ and the wells of the 24 -well plate into which the chambers were placed were filled with $500 \mu \mathrm{L}$ of RPMI-1640 medium containing $10 \%$ FBS. The chambers were incubated for $24 \mathrm{~h}$ in a humidified atmosphere at $37^{\circ} \mathrm{C}$. Subsequently, cells remaining on the upper surface of the membrane were removed with a cotton swap, and the chambers were stained with crystal violet solution to count the migrated cells through the $8 \mu \mathrm{m}$ pores to the lower surface of the membrane. Each membrane was photographed under an inverted microscope (Leica, Wetzlar, Germany) and cells at 3 randomly selected regions were counted.

\section{Western Blot Analysis}

Western blot analysis was performed to evaluate the Akt, phospho-AKT (pAKT), and phospho-GSK3 $\beta$ (pGSK3 $\beta$ ) level in HEp-2 cells treated with AZD5363. Briefly, HEp- 2 cells were plated at a density of $2.5 \times 10^{5}$ cells per well in 6 well plates and cell lysates were prepared using RIPA Lysis Buffer (EcoTech Biotechnology, Turkey) from cells treated with AZD5363 for $48 \mathrm{~h}$ at concentrations ranging from $1 \mu \mathrm{M}$ to $10 \mu \mathrm{M}$. Cell lysates were mixed with same volume of Laemmli buffer (EcoTech Biotechnology, Turkey) and boiled at $100^{\circ} \mathrm{C}$ for 5 minutes. Samples containing equal amounts of protein were separated with $10 \%$ SDS/PAGE and then transferred to nitrocellulose membranes. Membranes were blocked with 5\% nonfat dry milk (EcoTech Biotechnology, Turkey) in PBS$\mathrm{T}$ buffer at room temperature and then incubated at $4^{\circ} \mathrm{C}$ overnight with one of the following primary antibodies: $\beta$-Aktin (1:200, Santa Cruz Biotechnology, Dallas, TX, USA), Akt (1:200, Santa Cruz Biotechnology, Dallas, TX, USA), pAkt (1:100, Santa Cruz Biotechnology, Dallas, TX, USA), and pGSK3 $\beta$ (1:500, Santa Cruz Biotechnology, Dallas, TX, USA). After washing with PBS-T containing $0.1 \%$ Tween-20 for 3 times, membranes were probed with anti-mouse (1:2000, Santa Cruz Biotechnology, Dallas, TX, USA) or anti-rabbit (1:2000, Santa Cruz Biotechnology, Dallas, TX, USA) horseradish peroxidase (HRP)-linked secondary antibodies for $1 \mathrm{~h}$ at room temperature. Specific proteins were visualized using Pierce ECL Western Blotting Substrate (Thermo Scientific, Waltham, MA, USA) following the manufacturer's instructions.

\section{Statistical Analysis}

Numerical values were shown as mean \pm standard error of mean. Differences between groups were tested using Student's t test. A $p$ - value of $<0.05$ was accepted as statistically significant.

\section{RESULTS}

AZD5363 induced phosphorylation of AKT and reduced phosphorylation of its downstream effector GSK3 $\beta$

To investigate the effects of PI3K/AKT/mTOR pathway inhibition using AZD5363 in HEp-2 cells, we initially measured the relative protein levels of AKT, pAKT, and pGSK3 $\beta$. AZD5363 increased the phosphorylation level of AKT, which is in parallel with the previous results (Fig. 1). To validate the inhibition of PI3K/AKT/mTOR pathway, we evaluated the phosphorylation of GSK3 $\beta$ and found that AZD5363 sup- 


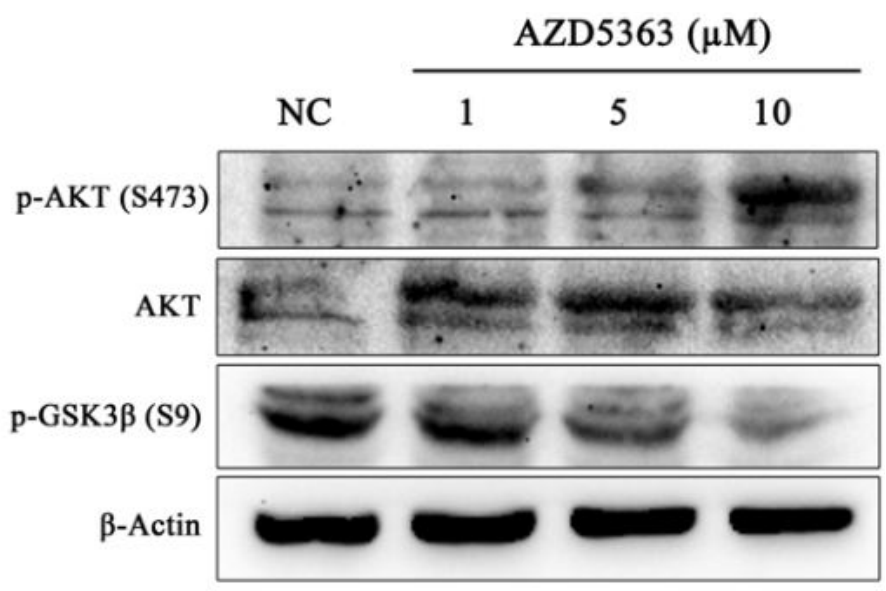

Fig. 1. A) Western Blot analysis of pAKT, AKT, and pGSK3 $\beta$ in cells treated with 1,5 , and $10 \mu \mathrm{M}$ AZD5363. B-Actin was used as loading control.

pressed pGSK $3 \beta$ in a dose-dependent manner (Fig. 1).These data suggest that AZD5363 successfully inhibits $\mathrm{PI} 3 \mathrm{~K} / \mathrm{AKT} / \mathrm{mTOR}$ signaling pathway in the HEp-2 laryngeal cancer cell line, which has been previously demonstrated to possess a constitutively active $\mathrm{PI} 3 \mathrm{~K} / \mathrm{AKT} / \mathrm{mTOR}$ axis.

\section{AZD5363 reduced the proliferative and anchorage de- pendent growth potential of HEp-2 cells in a dose and time dependent manner}

To determine the anti-proliferative effect of AZD5363 on HEp-2 cells, varying AZD5363 concentrations ranging from 1 to $10 \mu \mathrm{M}$ were exposed to cells for 24 and 48 hours. 24 hour treatment of AZD5363 did not affect the proliferative potential of HEp-2 cells, however, 5 and $10 \mu \mathrm{M}$ AZD5363 significantly decreased the relative number of cells compared to control. On the other hand, 48 hour after treatment, the viability of the HEp-2 cells was reduced effectively at all concentrations (Fig. 2A).

In order to evaluate the effect of AZD5363 on anchorage independent growth features of cells, soft agar assay was performed. Soft agar evaluates the aggressiveness of the cancer cells through testing the ability of cells to form colonies under anchorage-independent growth conditions on a semisolid surface.AZD5363 was found to inhibit the colony formation capabilities of HEp-2 cells in soft agar in a dose-dependent manner (Fig. 2B, C).

AZD5363 effectively induced apoptosis of HEp-2 cells

To evaluate the underlying mechanism for decrease in proliferative potential of HEp-2 cells treated with AZD5363, we assessed apoptosis using Annexin V-FITC Apoptosis Kit. Flow cytometry analysis showed that both 24 and 48 hours treatment of AZD5363 did not markedly altered the early apoptotic cells in HEp-2 cells (Fig. 3E, J). However, exposure to AZD5363 for 24 or 48 hours significantly enhanced the late apoptotic cells (Fig. 3A-D, F-I). $10 \mu \mathrm{M}$ of AZD5363 increased the ratio of late apoptotic cells from $0.69 \%$ to $1.55 \%$ and from $0.89 \%$ to $2.17 \%$ at the end of 24 and 48 hours, respectively (Fig. 3A, D, E, F, I, J).These results suggest that one of the possible
A

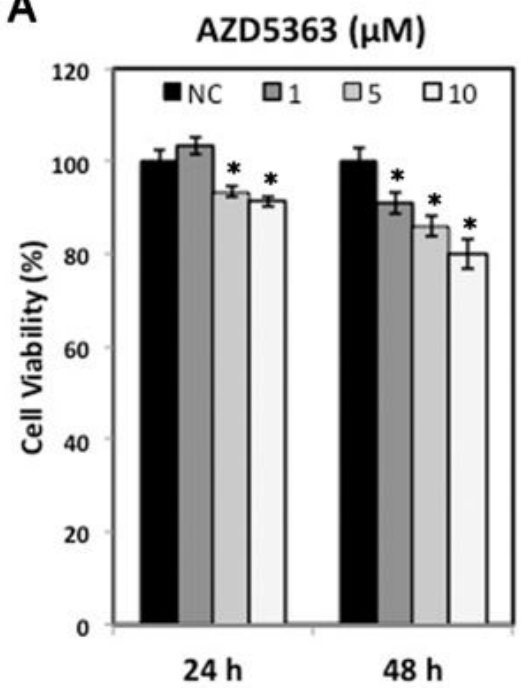

B

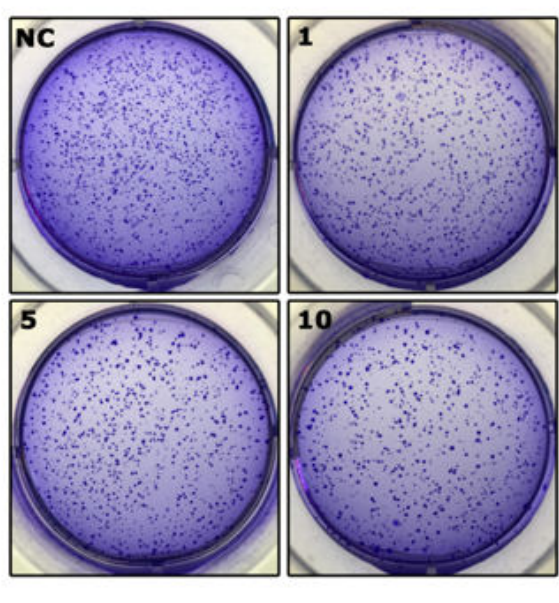

AZD5363 ( $\mu \mathrm{M})$

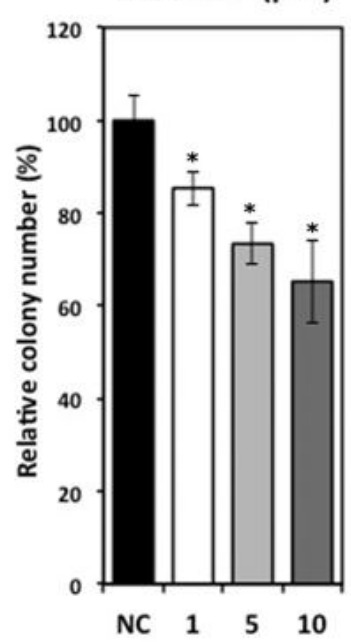

Fig. 2. A) Viability of cells exposed to1, 5, and $10 \mu \mathrm{M}$ AZD5363 for 24 or 48 hours. B) Colony formation abilities of HEp-2 cells treated 1, 5, and $10 \mu M$ AZD5363. Mean \pm Standard Error of Mean (SEM) is shown * $p<0.05$; t-test. 
A

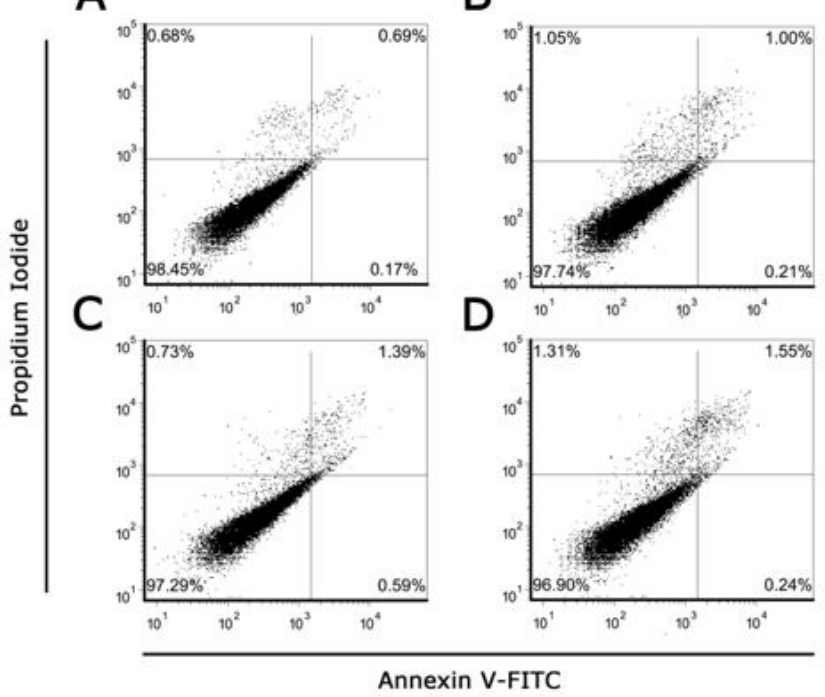

$\mathbf{F}$

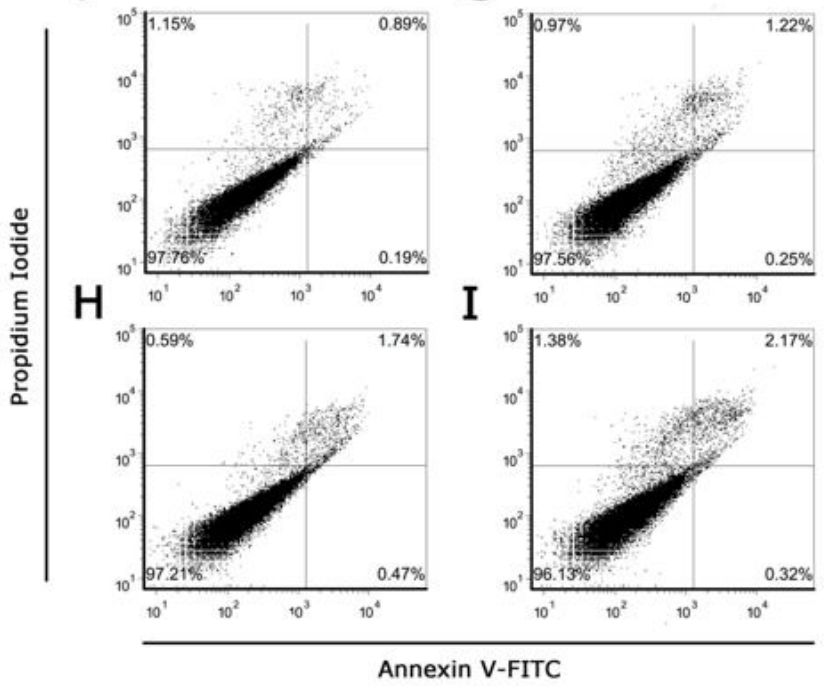

E

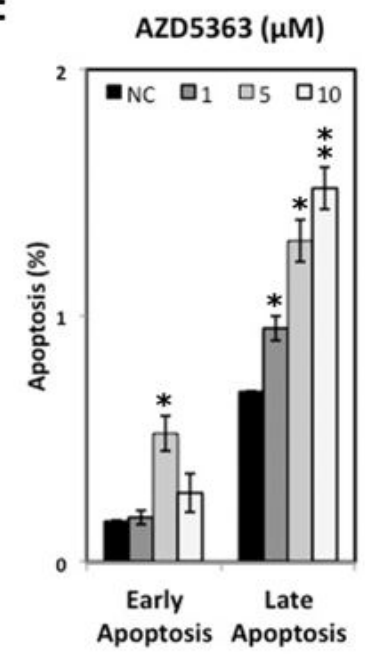

了

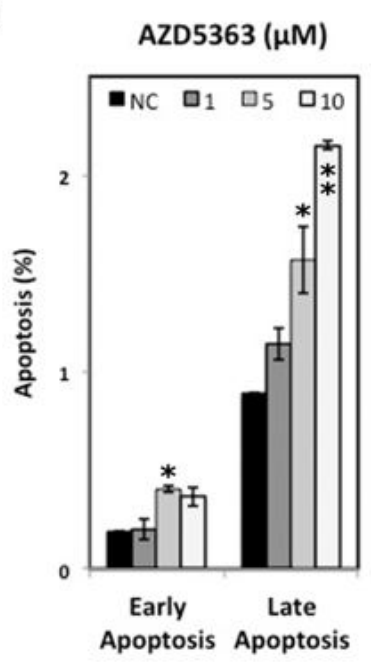

Fig. 3. The flow cytometry analysis of apoptosis in A) control, B) $1 \mu \mathrm{M}, \mathrm{C}) 5 \mu \mathrm{M}$, and D) $10 \mu \mathrm{M}$ AZD5363 for 24 hours. E) Relative apoptosis rates of control, 1,5 , and $10 \mu$ MAZD5363 treated

mechanisms of cell proliferation inhibition stems from the potential of AZD5363 to induce apoptosis in a dose and time-dependent manner in HEp-2 cells.

\section{AZD5363 reduced the ability of HEp-2 cells to migrate in a dose dependent manner}

To investigate the effect of AZD5363 on the ability of HEp-2 cells to migrate in vitro, we initially tested the migratory potential of HEp-2 cells treated with 1-5-10 $\mu$ M AZD5363 with scratch assay. Results demonstrated that although the migration capabilities of HEp-2 cells exposed to $1 \mu \mathrm{M}$ AZD5363 did not change, cells treated with 5 and $10 \mu \mathrm{M}$ AZD5363 cov- ered significantly smaller fraction of the wound in a dose dependent manner when compared to control cells (Figure 4A, C). Control cells could close more than $50 \%$ of the wound, whereas the HEp-2 cells treated with 5 and $10 \mu \mathrm{M}$ AZD5363 were able to close only $33 \%$ and $17 \%$, respectively.

We used transwell migration assay to further confirm the effect of AZD5363 on the migration capabilities of HEp-2 cells.As the most effective result was obtained at $10 \mu \mathrm{M}$ in the wound-healing assay, transwell migration assay was performed using this concentration. The migration rate of $10 \mu \mathrm{M}$ AZD5363 treated group decreased to $44 \%$ compared to the con- 
A

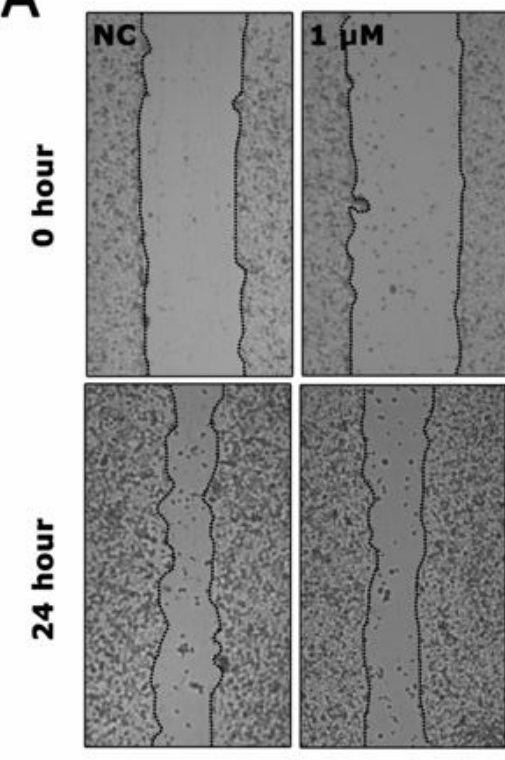

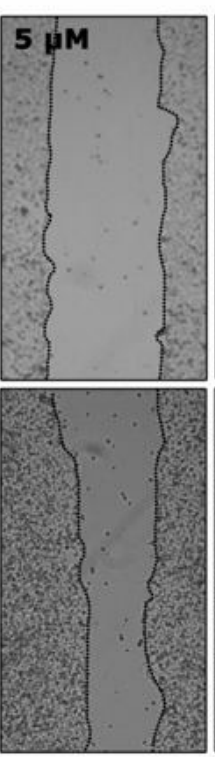

B
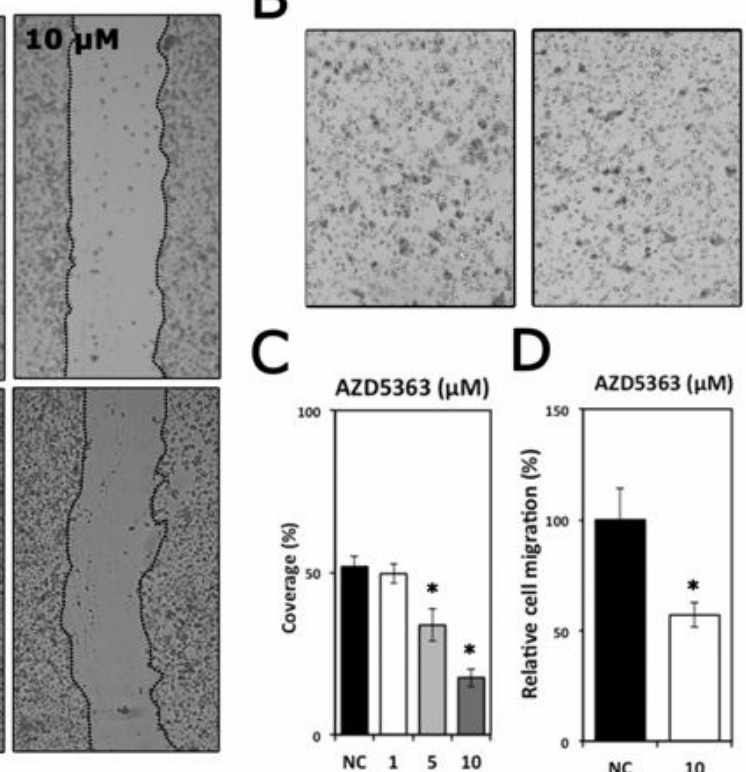

Fig. 4. A) The impacts of 1,5 , and $10 \mu M$ AZD5363 on HEp-2 cell migration evaluated with wound-healing assay, B) The mean relative wound closure of control, 1,5 , and $10 \mu \mathrm{M}$ AZD5363 treated cells. C) The impacts of 1,5 , and $10 \mu M$ AZD5363 on HEp-2 cell migration evaluated with Transwell migration assay, D) The mean relative migration rates of control, 1, 5, and $10 \mu$ M AZD5363 treated cells. Mean \pm SEM is shown * $p<0.05$; t-test.

trol group cells (Fig. 4B, C). This result was consistent with the scratch assay. These findings indicate that AZD5363 can effectively decrease the mobility of human laryngeal cancer HEp-2 cells.

\section{DISCUSSION}

$\mathrm{LCa}$ is one of the most frequent cancer types localized in the head and neck region worldwide, with an unchanged overall survival rate over the last decades [25]. Considering recent developments in the diagnostic and therapeutic options for LCa patients, an effective treatment strategy could not be presented due to its high metastatic and recurrent potential.

Currently chemotherapy serves as a standard therapeutic option for LCa, for especially those with nonoperable locally advanced disease, to reduce the systemic tumor burden and to sensitize cancer cells to radiotherapy [26, 27]. Nonetheless, with some success providing complete responses following chemotherapy in certain cases with LCa [27], present chemotherapy agents alone or together with other therapies cannot successfully provide complete clinical responses. This situation necessitates identification of adjuvant or neoadjuvant treatment modalities with potential to increase positive clinical outcomes.

Several recent evidences support deregulation of the PI3K-AKT-mTOR signaling pathway during carcinogenesis, metastasis, recurrence, and drug resistance [28]. Considering the potential involvement of PI3K-AKT-mTOR signaling pathway components in the acquisition of important hallmark capabilities of cancer, several novel small molecule inhibitors targeting PI3K, AKT or mTOR were developed [29].

Among those, inhibitors of AKT, which is the master regulator of this pathway, attract more attention to be used as therapeutic agents against various cancer types [30]. AKT has been found to be constitutively active in laryngeal HEp-2 cells, emphasizing its importance as a therapeutic target in LCa [24]. Besides, abnormal expression of AKT isoforms was associated with several clinico-pathological parameters including tumor site, lymph node metastasis, clinical stage, and shorter overall survival in LCa patients, which projects the potential clinical value of AKT inhibition as a putative adjuvant therapy $[16,17]$. As one can expect, inactivation of AKT and thus its downstream effectors in a recent study utilized a potential AKT inhibitor, chamaejasmine, induced apoptosis in LCa cells both 
in vitro and in vivo [24].

AZD5363, as a novel new-generation small molecule with catalytic inhibitor activity against all AKT isoforms, have potential to inhibit the phosphorylation status of AKT downstream targets, including that of GSK3 $\beta[19,31]$. In our study, we demonstrate increased pAKT in HEp-2 cells upon AZD5363 treatment, which is in parallel with the previous researches carried out with different types of cancer cells [22, 23]. AZD5363 treatment has been reported to cause its hyperphosporylation due to a secondary feedback mechanism activated as a result of inhibition of its kinase activity [19]. Being the only AKT inhibitor with the potential to induce AKT phosphorylation among many other well-known AKT inhibitors like, LY294002, MK-2206, and wortmannin, it reduces the pGSK3 $\beta$ level as other AKT inhibitors [32]. Our results demonstrated a concentration dependent inhibition of GSK3 $\beta$, pointing successful inhibition of PI3K-AKTmTOR signaling pathway in those cells treated with AZD5363.

We further evaluated the affects of AZD5363 in vitro on the phenotypes associated with cancer aggressiveness using HEp-2 cells. Our results demonstrated that AZD5363 significantly inhibited proliferative and anchorage independent growth potential of HEp-2 cells in a dose and time dependent manner through inducing apoptosis. Further analysis of migratory potential in cells treated with AZD5363 showed also inhibitory potential of AZD5363 on the migration capacity of HEp-2 cells. On a protein microarray analysis carried out with tumor samples, confirmed increased phosphorylated AKT levels and demonstrated decreased Ki67 staining pointing its anti-proliferative capacity in vivo [20]. In other studies, AZD5363 lead to cell-cycle arrest in all cells studied, through inhibition of cell cycle related genes such as $\mathrm{Rb}$ and Cyclin $\mathrm{D}$, and induction of apoptosis via elevated levels of apoptosis related gene such as CASP9 [30].

Interestingly, a recent study demonstrated that AZD5363 treatment more effectively killed cells with activating mutations in PIK3CA and/or loss of PTEN function [30]. This implies an important point for targeting LCa tumors, where sequence analysis for PI3K/AKT/mTOR pathway components might increase the efficacy of a potential therapy utilizing AZD5363. Moreover, Choi et al. [32] demonstrated that co-treatment of LY294002 or MK-2206 with AZD5363 lead to a significant reduction in the level of phosphorylated AKT. Considering MK-2206 is a clinically used agent, they offered synergistic use of MK-2206 and AZD5363 as potential therapeutic options for patients with cancer [32]. The success of their synergistic use might be evaluated in further in vitro and in vivo studies to demonstrate the feasibility of AZD5363-based sensitization therapies in LCa.

\section{CONCLUSION}

In conclusion, further comprehensive molecular and clinical research may elucidate the potential use of AZD5363 in LCa therapy in detail. However, the current study has revealed putative functions of AZD5363 in vitro that might be utilized against LCa.

\section{Conflict of interest statement}

Fatma Şanlı, Neslişah Barlak, Ahsen Kılınç, Özel Çapık, and Abdülmelik Aytatlı declare that they have no conflict of interests. Ömer Faruk Karataş holds stocks in EcoTech Biotechnology. The terms of this arrangement have been reviewed and approved by Erzurum Technical University in accordance with its policy on objectivity in research.

\section{Funding Source}

This work was partially supported by the Scientific Research Projects of Erzurum Technical University under Grant 2017/19.

\section{REFERENCES}

1. Armstrong WB, Vokes DE, Verma SP. Malignant tumors of the larynx. In: Flint PW, Haughey BH, Lund V, Niparko JK, Robbins KT, Tomas JP, et al., eds. Cummings Otolaryngology - Head and Neck Surgery. 6th. ed., Philadelphia, PA: Elsevier Inc., Sander; 2015: pp.1601-33.e10.

2. Yilmaz SS, Guzel E, Karatas OF, Yilmaz M, Creighton CJ, Ozen M. MiR-221 as a pre- and postoperative plasma biomarker for larynx cancer patients. Laryngoscope 2015;125:E377-81.

3. Jaipuria B, Dosemane D, Kamath PM, Sreedharan SS, Shenoy VS. Staging of Laryngeal and Hypopharyngeal Cancer: Computed Tomography versus Histopathology. Iran J Otorhinolaryngol 2018;30:189-94.

4. Zhang Y, Hu H. Long non-coding RNA CCAT1/miR-218/ZFX axis modulates the progression of laryngeal squamous cell cancer. 
Tumour Biol 2017;39:1010428317699417.

5. Yu Q, Zhang X, Ji C, Yang H, Gao M, Hong S, et al. Survival analysis of laryngeal carcinoma without laryngectomy, radiotherapy, or chemotherapy. Eur Arch Otorhinolaryngol 2012;269:2103-9.

6. Wu Y, Zhang Y, Niu M, Shi Y, Liu H, Yang D, et al. Wholetranscriptome analysis of CD133+CD144+ cancer stem cells derived from human laryngeal squamous cell carcinoma cells. Cell Physiol Biochem 2018;47:1696-710.

7. Cantley LC. The phosphoinositide 3-kinase pathway. Science 2002;296:1655-7.

8. Gupta AK, McKenna WG, Weber CN, Feldman MD, Goldsmith JD, Mick R, et al. Local recurrence in head and neck cancer: relationship to radiation resistance and signal transduction. Clin Cancer Res 2002;8:885-92.

9. Pérez-Tenorio G, Alkhori L, Olsson B, Waltersson MA, Nordenskjöld B, Rutqvist LE, et al. PIK3CA mutations and PTEN loss correlate with similar prognostic factors and are not mutually exclusive in breast cancer. Clin Cancer Res 2007;13:3577-84.

10. Harima Y, Sawada S, Nagata K, Sougawa M, Ostapenko V, Ohnishi T. Mutation of the PTEN gene in advanced cervical cancer correlated with tumor progression and poor outcome after radiotherapy. Int J Oncol 2001;18:493-7.

11. Bedolla R, Prihoda TJ, Kreisberg JI, Malik SN, Krishnegowda NK, Troyer DA, et al. Determining risk of biochemical recurrence in prostate cancer by immunohistochemical detection of PTEN expression and Akt activation. Clin Cancer Res 2007;13:3860-7.

12. Snietura M, Jaworska M, Mlynarczyk-Liszka J, Goraj-Zajac A, Piglowski W, Lange D, et al. PTEN as a prognostic and predictive marker in postoperative radiotherapy for squamous cell cancer of the head and neck. PLoS One 2012;7:e33396.

13. Liu P, Cheng H, Roberts TM, Zhao JJ. Targeting the phosphoinositide 3-kinase pathway in cancer. Nat Rev Drug Discov 2009;8:627-44.

14. Bellacosa A, Kumar CC, Di Cristofano A, Testa JR. Activation of AKT kinases in cancer: implications for therapeutic targeting. Adv Cancer Res 2005;94:29-86.

15. Altomare DA, Testa JR. Perturbations of the AKT signaling pathway in human cancer. Oncogene 2005;24:7455-64.

16. Chen Y, He Y, Zhang S, Li L, Zhu X, Liu Y. [The expression of oncogene AKT2 in laryngeal squamous cell carcinoma and its clinical significance]. Lin Chung Er Bi Yan Hou Tou Jing Wai Ke Za Zhi. 2009;23:539-541, 545. [Article in Chinese]

17. Dionysopoulos D, Pavlakis K, Kotoula V, Fountzilas E, Markou K, Karasmanis U, et al. Cyclin D1, EGFR, and Akt/mTOR pathway. Potential prognostic markers in localized laryngeal squamous cell carcinoma. Strahlenther Onkol 2013;189:202-14.

18. Crabb SJ, Birtle AJ, Martin K, Downs N, Ratcliffe I, Maishman T, et al. ProCAID: a phase I clinical trial to combine the AKT inhibitor AZD5363 with docetaxel and prednisolone chemotherapy for metastatic castration resistant prostate cancer. Invest New Drugs 2017;35:599-607.

19. Davies BR, Greenwood H, Dudley P, Crafter C, Yu D-H,
Zhang J, et al. Preclinical pharmacology of AZD5363, an inhibitor of AKT: pharmacodynamics, antitumor activity, and correlation of monotherapy activity with genetic background. Mol Cancer Ther 2012;11:873-87.

20. Toren P, Kim S, Cordonnier T, Crafter C, Davies BR, Fazli L, et al. Combination AZD5363 with enzalutamide significantly delays enzalutamide-resistant prostate cancer in preclinical models. Eur Urol 2015;67:986-90.

21. Lamoureux F, Thomas C, Crafter C, Kumano M, Zhang F, Davies BR, et al. Blocked autophagy using lysosomotropic agents sensitizes resistant prostate tumor cells to the novel Akt inhibitor AZD5363. Clin Cancer Res 2013;19:833-44.

22. Feng S, Shao L, Castro P, Coleman I, Nelson PS, Smith PD, et al. Combination treatment of prostate cancer with FGF receptor and AKT kinase inhibitors. Oncotarget 2017;8:6179-92.

23. De Velasco MA, Kura Y, Yoshikawa K, Nishio K, Davies BR, Uemura H. Efficacy of targeted AKT inhibition in genetically engineered mouse models of PTEN-deficient prostate cancer. Oncotarget 2016;7:15959-76.

24. Wang Y, Zhao Y, Liu Y, Tian L, Jin D. Chamaejasmine inactivates Akt to trigger apoptosis in human HEp-2 larynx carcinoma cells. Molecules 2011;16:8152-64.

25. Steuer CE, El-Deiry M, Parks JR, Higgins KA, Saba NF. An update on larynx cancer. CA Cancer J Clin. 2017;67:31-50.

26. Adelstein DJ, Li Y, Adams GL, Wagner H Jr, Kish JA, Ensley $\mathrm{JF}$, et al. An intergroup phase III comparison of standard radiation therapy and two schedules of concurrent chemoradiotherapy in patients with unresectable squamous cell head and neck cancer. J Clin Oncol 2003;21:92-8.

27. Haigentz M Jr, Silver CE, Hartl DM, Takes RP, Rodrigo JP, Robbins KT, et al. Chemotherapy regimens and treatment protocols for laryngeal cancer. Expert Opin Pharmacother 2010;11:1305-16.

28. Polivka J, Janku F. Molecular targets for cancer therapy in the PI3K/AKT/mTOR pathway. Pharmacol Ther 2014;142:16475.

29. Zhang Y, Zheng Y, Faheem A, Sun T, Li C, Li Z, et al. A novel AKT inhibitor, AZD5363, inhibits phosphorylation of AKT downstream molecules, and activates phosphorylation of mTOR and SMG-1 dependent on the liver cancer cell type. Oncol Lett 2016;11:1685-92.

30. Ribas R, Pancholi S, Guest SK, Marangoni E, Gao Q, Thuleau A, et al. AKT Antagonist AZD5363 influences estrogen receptor function in endocrine-resistant breast cancer and synergizes with fulvestrant (ICI182780) in vivo. Mol Cancer Ther 2015;14:2035-48.

31. Tamura K, Hashimoto J, Tanabe Y, Kodaira M, Yonemori K, Seto T, et al. Safety and tolerability of AZD5363 in Japanese patients with advanced solid tumors. Cancer Chemother Pharmacol.2016;77:787-95.

32. Choi AR, Kim JH, Woo YH, Cheon JH, Kim HS, Yoon S. Co-treatment of LY294002 or MK-2206 with AZD5363 attenuates AZD5363-induced increase in the level of phosphorylated AKT. Anticancer Res 2016;36:5849-58. 